\title{
Assessment of the Adoption of Mobile Parking Management System in the Parking Industry in Nairobi County: A Case of Lulu East Africa
}

\author{
Jades Kalunda Muema \\ Information Technology \\ Dedan Kimathi University of \\ Technology \\ Kenya
}

\author{
Benjamin Kyambo \\ Faculty of Information Sciences \\ Kisii University \\ Kenya
}

\author{
Benjamin Kyambo \\ School of Information Sciences \\ KCA University \\ Kenya
}

\author{
Caroline Kirichu \\ Faculty of Information Sciences \\ Kisii University \\ Kenya
}

\author{
Kennedy Senagi \\ Information Technology \\ Dedan Kimathi University of Technology \\ Kenya
}

\begin{abstract}
In the parking industry, savings can be made by providing alternative payment options for customers, such as cashless parking schemes, and providing the parking workforce with more sophisticated equipment. This technological change is expected to contribute to the development of more flexible, convenient and efficient parking services, increases revenue and customer satisfaction. This study assesses the adoption of mobile parking management information systems in the parking industry in Nairobi County with a special focus on Lulu East Africa. The researcher adopted a descriptive research design and the primary data was collected using questionnaires from the sample population of 60 comprising of workers and clients. This data was analyzed using SPSS version 21 and presented using distribution tables and graphs. The research findings indicated that Nairobi county and the parking industry were generally ready to adopt the mobile parking management system whose success is subject to a detailed feasibility study, although as with any technological adoption it is bound to face some barriers which can be overcome.
\end{abstract}

KEYWORDS: Adoption, mobile parking management system

\section{INTRODUCTION}

This sections presents the research background, problem statement, research objectives, significance of the research and the conceptual frame work.

\subsection{Research Background}

Often city officials presume that the providing of more parking spaces for the citizens means meeting the mobility needs. On the contrary, every car that is on the road needs a place to be parked: it is a key issue in almost all urban areas. (Bayless and Neelakantan, 2012). Evidence suggests that savings can be made by providing alternative payment options for customers, and providing the parking workforce with more sophisticated equipment. This technological change is expected to contribute to the development of more flexible and convenient parking services, raising public perceptions and expectations of the industry, whilst driving parking employer demand for the specialist skills to install, use and maintain equipment. (Walker, 2011).

Traffic flow, allocation and availability of parking space within the streets of Nairobi, is a major concern to for every motorist. Parking is managed by the former City Council of Nairobi and this exercise is currently a nightmare for the officials of the county government. (Kinyanjui, 2010).
Lulu East Africa Ltd, an expansive yard located on NSSF land on Kenyatta Avenue. The company has various approaches of car park management and allocation depending on the various client needs. Lulu East Africa seeks to improve its service delivery to gain competitive advantage, improve revenue collection and customer satisfaction. In this regard the management seeks to adopt technology to streamline its processes and provide convenient ways of engaging with the clients. Mobile management system is an option for them especially considering the wide use of mobile payment by majority of its target market, availability of the necessary technology and the convenience it brings. (Lulu East Africa, 2014).

\subsection{Statement of the Problem}

It is estimated that nearly $30 \%$ of urban congestion is created by drivers cruising for parking. Finding a parking space in most metropolitan areas, especially during the rush hours, is difficult for drivers. The difficulty arises from not knowing where the available spaces may be at that time; even if known, many vehicles may pursue very limited parking spaces to cause serious traffic congestion. (Wang and Wenbo, 2013). 
Modern services are designed to get drivers to their ultimate destination without searching and the uncertainty related to cost, travel time, payment, and other practical considerations. In exchange for this convenience, smart parking service providers take advantage of consumers' willingness to pay a marginal mark-up over existing parking fees. It is this need coupled with the extensive use of mobile devices and the convenience of mobile payment that has given rise to the need for inclusion on mobile devices in the parking industry to improve performance and gain a competitive edge. (BPA, 2012; Wang and Wenbo, 2013). In line with this, there arises a challenge in the parking industry as far as adoption of mobile technology adoption is concerned since in Kenya it is rather new with limited studies and information especially in the case of Kenya; hence treated with caution. This study seeks to fill this gap and will present a critical discussion on the dynamics of the adoption of mobile parking management system and identifying potential gaps for future research.

\subsection{Research Objectives}

The main objective of this study is to assess the adoption of mobile parking management system in Nairobi County with a special focus on Lulu East Africa; its specific objectives are:

i. To examine the current state of management of parking at Lulu East Africa

ii. To investigate the successful adoption of mobile parking management information at Lulu East Africa.

iii. To conduct a pre-feasibility analysis on the adoption of mobile parking management system at Lulu East Africa

\subsection{Significance of the Study}

The study will be significant to Lulu East Africa Ltd in providing valuable information in their efforts to adopt technology in their operations that will go a long way in not only helping them in decision making but also in anticipating the challenges that come with the adoption and recommendations of the measures on how to counter them. Investors in the parking industry will stand to benefit from this study to make informed decisions on mobile technology adoption and also benefit from its features. This study and consequent successful adoption of mobile parking management system will help make parking a nonevent for drivers where it will be so easy and painless that it no longer becomes an issue. The study will add to the existing body of knowledge and it will increase awareness on not only the variables that impact successful adoption but also barriers to successful adoption of mobile management systems and their counter measures. In this regard further insights in this issue are of great importance to scholars in the parking industry and information technology in general. The stakeholders might use the research findings to evaluate the adoption of mobile technology and the extent to which it affects the parking industry in advent of improving its performance.

\subsection{Conceptual Framework}

Perceived usefulness refers to the degree to which a person believes that using a particular system would enhance his or her job performance. Perceived ease of use refers to the degree to which a person believes that using a particular system would be free of free of physical and mental effort. Social influence is defined as the degree to which an Individual perceives that important others believe he or she should use the new system. Facilitating conditions refer to the degree to which an individual believes that an organizational and technical infrastructure exists to support technology use.

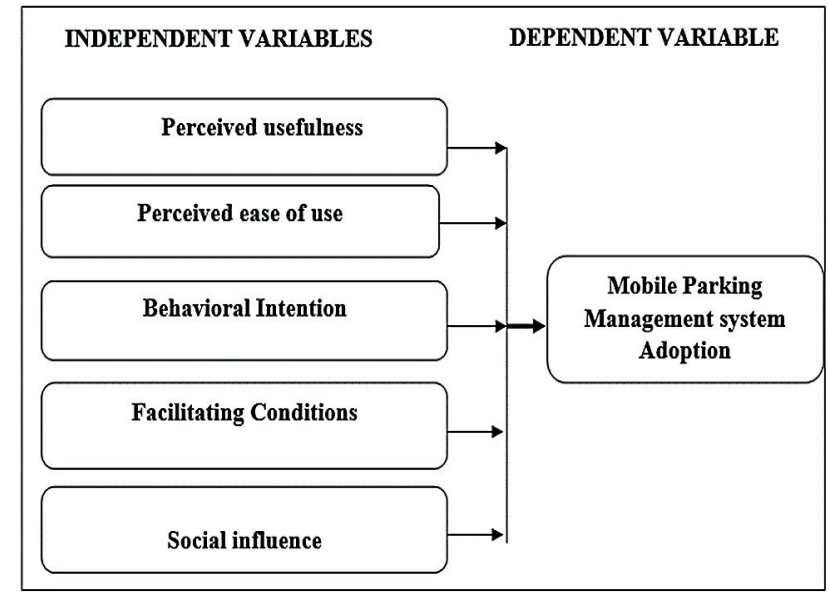

Figure 1: Conceptual framework

\section{LITERATURE REVIEW \\ 2.1. Features of Mobile Parking Information System}

Mobile payments; this refers to a variety of financial transactions initiated with a mobile device.

Real-Time Parking Information; Mobile applications on smartphones are a significant area of growth for the parking industry, with an increasing number of customers relying on apps to get information on a car park's precise location, opening hours, tariff and facilities. (IPI, 2012: Flood et al, 2013). Automatic Number Plate Recognition (ANPR); the use of cameras to take timed photos of the vehicle (with close ups of the number plate) entering and leaving the car park. These photos are then used to calculate how long a vehicle has been parked.

\subsection{Mobile Parking Management System Adoption Feasibility}

During feasibility analysis we should consider that systems are adopted in businesses for two primary reasons: to take advantage of business opportunities and to solve business problems. A pre-feasibility study (PFS) is broadly defined as preparatory studies enabling funders to undertake a 
successful feasibility study for a particular investment opportunity. (Hart and Gregor 2010).

This analysis can be categorised into technical, economic and operational feasibility. Technical feasibility which is carried out to determine whether the company has the capability, in terms of software, hardware, personnel and expertise, to handle the completion of the proposed solution. (Blanchard and Fabrycky, 2010). Economic feasibility; O'Brien and Marakas (2011), indicate that the purpose of the economic feasibility assessment is to determine the positive economic benefits to the organization that the proposed system will provide. It includes quantification and identification of all the benefits expected. This assessment typically involves a cost/ benefits analysis. Operation feasibility; is a measure of how well a proposed system solves the problems, and takes advantage of the opportunities identified during scope definition and how it satisfies the requirements identified in the requirements analysis. It focuses on the willingness and ability of the management, employees, customers, suppliers, and others to operate, use, and support the proposed solution. (Hart and Gregor 2010).

\subsection{Theoretical Framework}

There have been several theoretical models, primarily developed from theories in psychology and sociology employed to explain technology acceptance and use. They include:

\subsubsection{Technology Acceptance Model (TAM)}

Technology Acceptance Model has been developed by Davis (1989) is one of the most popular research models to predict use and acceptance of information systems and technology by individual users. According to TAM individuals' intention to use technology determines the actual use of the application and attitudes toward technology affect the intention. Perceived usefulness and perceived ease of use factors are affected by various external variables such as level of education, gender, or organizational features such as training in computer use. (Davis et al., 1989; Davis and Venkatesh, 2004; Venkatesh et al., 2012).

\subsubsection{Theory of Reasoned Actions (TRA)}

Fishbein and Ajzen (1975) developed TRA to define the links between the beliefs, attitudes, norms, intentions, and behaviours of individuals. The theory assumes that a person's behaviour is determined by the person's behavioural intention to perform it, and the intention itself is determined by the person's attitudes and his or her subjective norms towards the behaviour. The subjective norm refers to "the person's perception that most people who are important to him think he should or should not perform the behaviour in question" (Fishbein and Ajzen, 1975, 302).

www.ijcat.com

\subsubsection{Unified Theory of Acceptance and Use of Technology (UTAUT)}

The purpose of UTAUT is to explain a user's intentions to use ICT and the subsequent user behaviour. The model considers four constructs as direct determinants of user acceptance and usage behaviour, namely performance expectancy, effort expectancy, social influence, and facilitating conditions. The authors stated that UTAUT provides a tool for managers to assess the likelihood of success of technology introductions and to understand the drivers of acceptance in order to design interventions, which include, e.g., training or marketing. UTAUT focuses on users who may be less willing to adopt and use new systems. (Venkatesh et al., 2003; Yu, 2012).

\section{RESEARCH METHODOLOGY}

This study will adopt a descriptive research design. A sample size of 60 respondents composed of staff and customers of Lulu East Africa were selected. The researcher used questionnaires that were formulated based on the research objectives to collect primary data that was later analysed using SPSS. Content analysis was used to analyse the data while descriptive analysis such as mean, frequencies and percentages were be used to analyse the data. Also the inferential statistics such as correlation models and Chi square will be used. Tables and charts were used for data presentation.

\section{DATA ANALYSIS PRESENTATIONS}

AND

As indicated in table 4.1, the respondents were split between the customers and Lulu East Africa staff. The customers made up $50 \%$ of the respondents, normal employees $23 \%, 4$ supervisors, 1 manager and two directors.

Table 1: Organizational position

\begin{tabular}{lcc}
\hline \hline & Frequency & Percentage \\
\hline Director & 2 & 3.3 \\
Manager & 1 & 1.7 \\
Supervisor & 4 & 6.7 \\
Employee & 23 & 38.3 \\
Customer & 30 & 50 \\
Total & $\mathbf{6 0}$ & $\mathbf{1 0 0 . 0 0}$ \\
\hline \hline
\end{tabular}

\subsection{Access to Mobile Devices}

According to the survey, $86.7 \%$ of the respondents owned a phone, tablet and or a PDA; all of them had access to conventional forms of mobile payment while $90 \%$ had access to alternative forms of mobile payment such as mobile banking as indicated in figure 1. This is key to the mobile paring adoption since the entire concept is based on mobile device with mobile payment being one of the key functionalities of the system. 


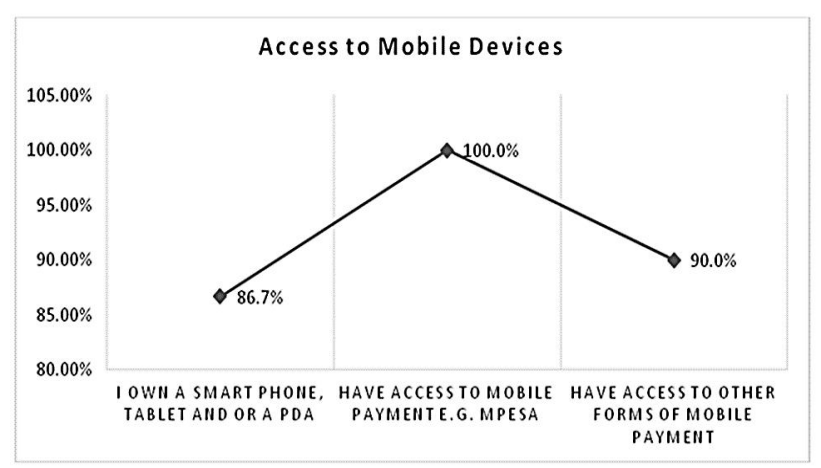

Figure 1: Access to mobile devices

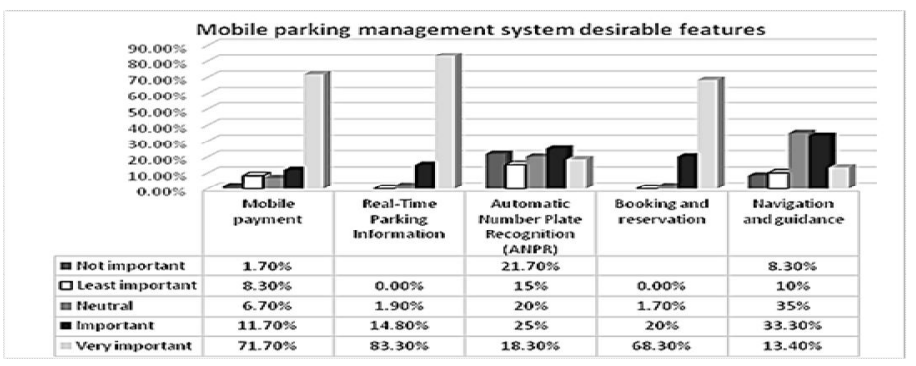

Figure 2: Desirable features in mobile parking management system

\subsubsection{Perceived Usefulness}

The survey response indicated that majority of the respondents felt that the mobile parking management system would to a great extent be overall useful in parking management, improvement of job performance was second. In essence, there was a consensus that the mobile parking management system would impact all aspects of parking management as indicated in figure 3 below.

Figure 3: Impact of adoption of mobile parking

Table 2: Process automation

\begin{tabular}{lcc}
\hline \hline & Frequency & Percentage \\
\hline Some activities are & 47 & \\
automated and others are & & 78.3 \\
manual & 13 & 21.7 \\
Don't Know & $\mathbf{6 0}$ & $\mathbf{1 0 0 . 0 0}$ \\
Total &
\end{tabular}

The survey determined as shown in table 2 above that majority of the respondents $78.3 \%$ had some knowledge on the operation of Lulu East Africa, and that their activities were a combination of manual and computerized.

\subsection{Desirable Features in Parking Management System}

The findings established that provision of real time parking information, according to the survey was the most desirable feature of the parking management system according to $83.3 \%$ of the respondents, this was followed by mobile payment with $71.7 \%$. Automatic Number Plate recognition was the least important feature to the respondents with only $43 \%$ feeling that this was an important feature. A considerable number of respondents $68.3 \%$ were of the opinion that booking and reservation was also a feature they would like integrated in the mobile parking management system as shown in figure 2 .

$\underline{\text { www.ijcat.com }}$ management system

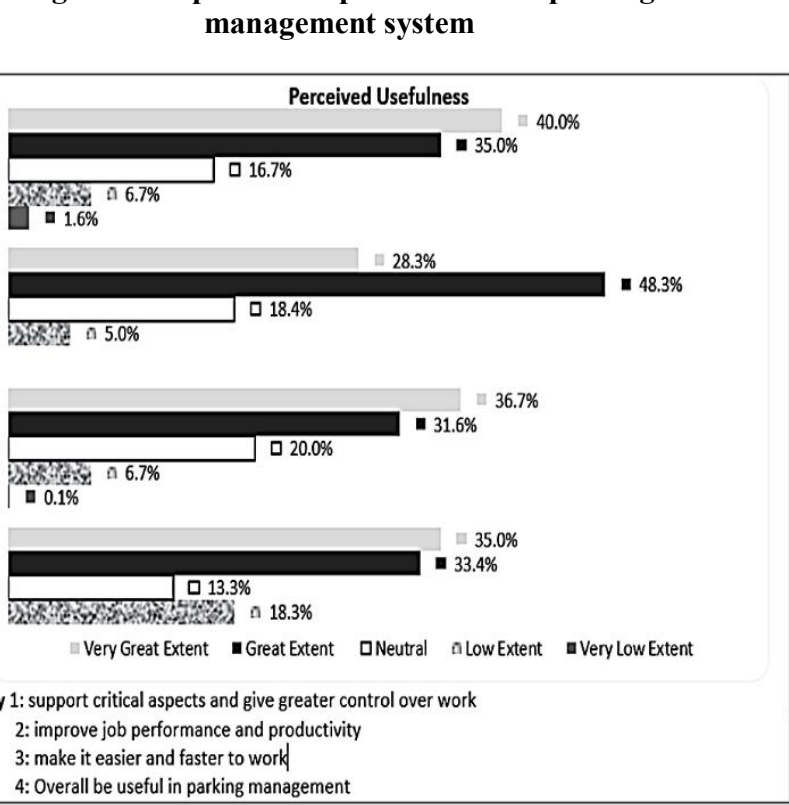

\subsubsection{Perceived Ease of Use}

In regards to the respondents perception on the ease of use of the new mobile system, the survey showed that $63.3 \%$ of the respondents felt that the mobile parking management system would be both easy for them to learn and operate and easy for them to get it to do what they wanted to do. Also, a significant number of respondents $63.4 \%$ were of the opinion that generally they would find the system easy to use as indicated in figure 4. This response could be attributed to the fact that majority of them have access to mobile devices and mobile forms of payment and as such have experience with them. The constant $3 \%$ who were reluctant about the system could be 
deduced to be the ones without access to smart devices and lower education levels.

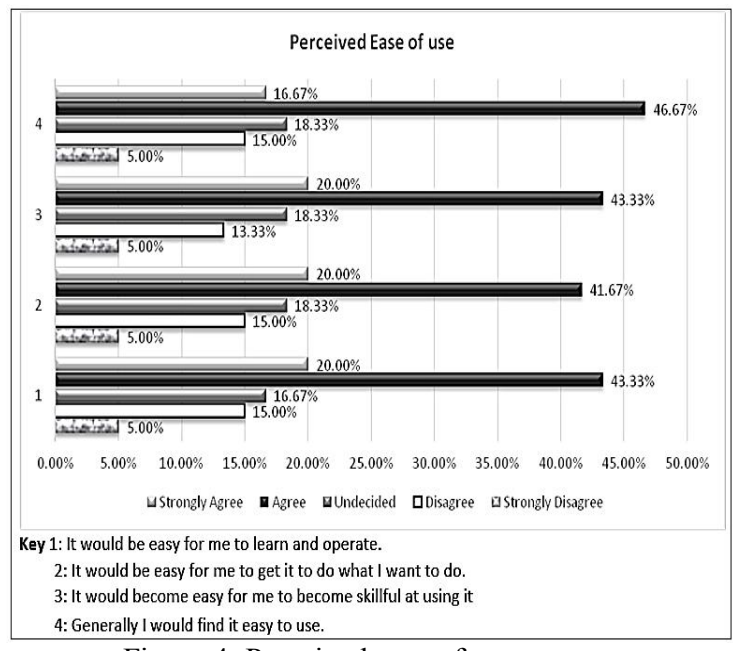

Figure 4: Perceived ease of use

\subsubsection{Behavioural Intention}

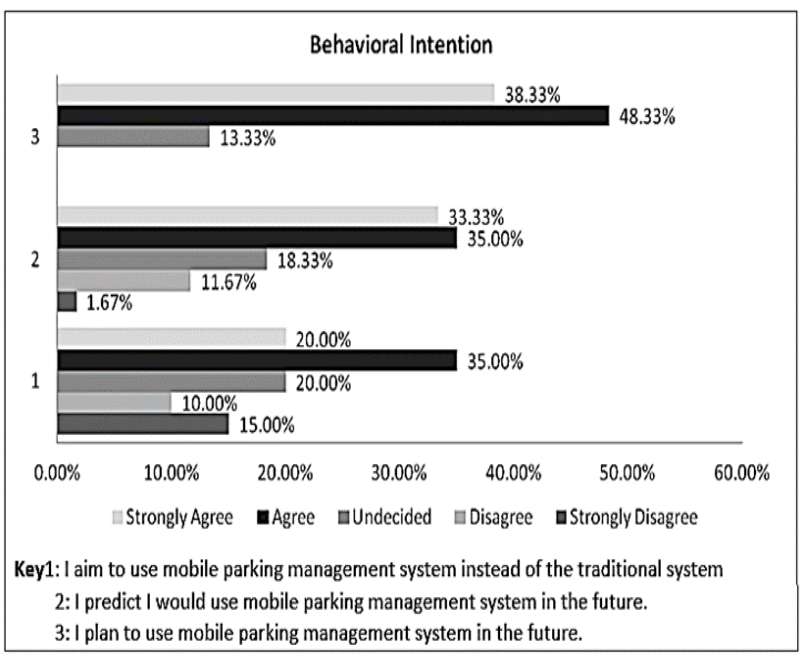

Figure 5: Behavioural Intention

The survey shows that generally the respondents were intended or were willing to adopt mobile parking management system (and any mobile technology) at some time in future $(86.7 \%) ; 88.3 \%$ predicted they would use mobile parking management system in future while $55 \%$ aim to use mobile parking management system instead of the traditional system as shown in figure 5 .

\subsubsection{Social Influence}

In regards to social influence of the respondents $65 \%$ agreed that that management system as depicted in figure 6 .

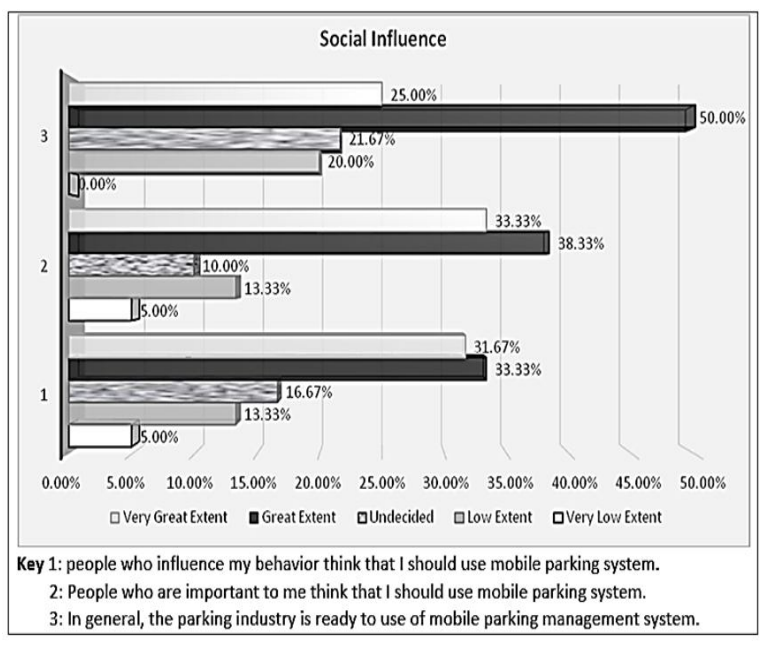

Figure 6: Social Influence

\subsubsection{Facilitating Conditions}

According to the survey majority of the respondents $91.7 \%$, agreed that their living and working environment supports them to use mobile parking management system and also that using mobile parking management system is compatible with their life. In regards to availability of sufficient technological infrastructure to support mobile parking management system, $71 \%$ of the respondents felt that this was the case; however, as indicated in figure 7 the respondents were not so sure about the availability of help when they get problems in using mobile parking management system as only $40 \%$ agreed to this.

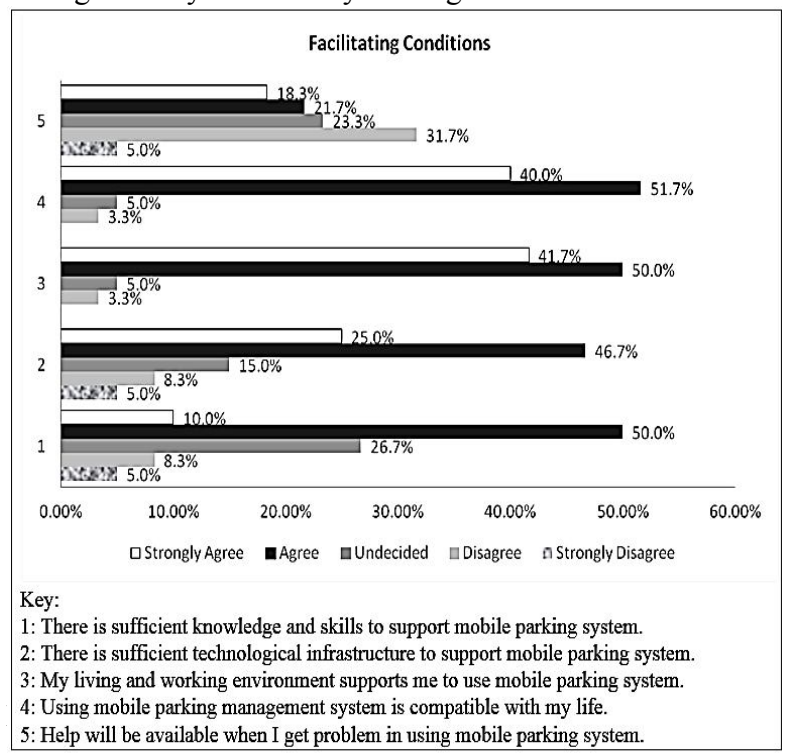

Figure 7: Facilitating conditions 


\subsection{Pre-feasibility Study}

\subsubsection{Technical Feasibility}

Lulu East Africa according to the survey has the technical capability to facilitate to fruition the adoption of mobile parking management system. According to $83 \%$ of the respondents they are able to acquire and or lease all the hardware and network resources required. All the respondents agreed that the company was able to restructure their organization and its processes to accommodate the changes that come with the adoption of the new system and get the necessary technical support required for the system. As indicated in figure 8, 97\% of the staff felt that software resources such as mobile apps would also be acquired as required by the mobile management system.

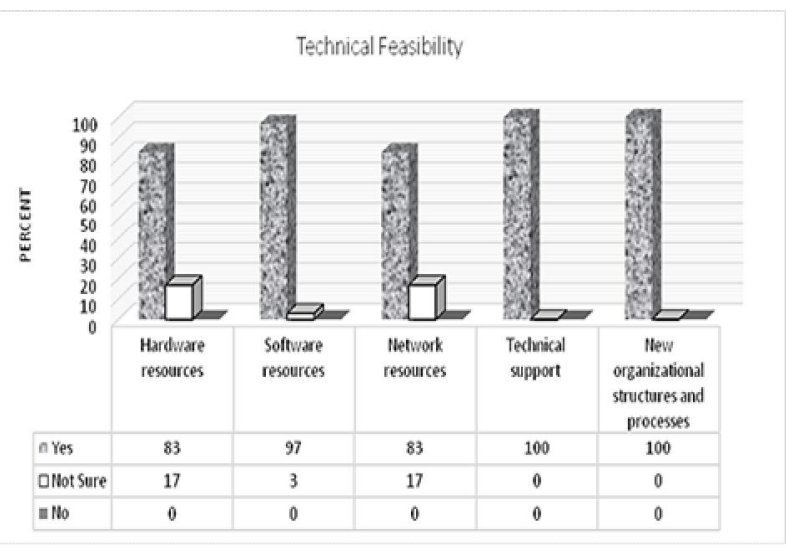

Figure 8: Technical feasibility

\subsubsection{Economic Feasibility}

The survey indicated as shown in figure 9 that majority of the respondents $90 \%$ agreed that adopting the system is a good business decision after a cost benefit analysis; 65\% felt that the company stood to gain competitive advantage hence increase revenue as a result of the mobile management system adoption while $64 \%$ were of the opinion that generally benefits of the mobile system will exceed the costs of adopting and operating it. The initial investment on the system adoption would be high but there was expectation of Return on Investment (ROI) in reasonable time according to $58 \%$ of the respondents.

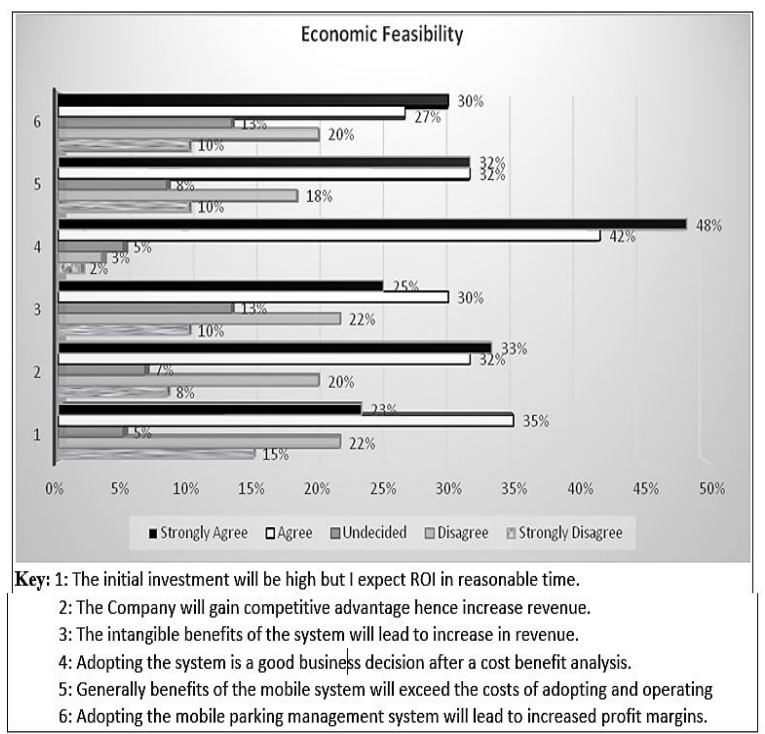

Figure 9: Economic feasibility

\subsubsection{Functional/Operational Feasibility}

Majority of the respondents 88 and $87 \%$ respectively as shown in figure 4.11 were of the opinion that adopting mobile parking management system will maximize efficiency of parking payment system and that of parking facilities and services; $81 \%$ agreed that the adoption would improve customer experience and satisfaction. However a lower percentage $(46 \%)$ were convinced that the mobile parking system would will share real time parking information with other agencies and stakeholders.

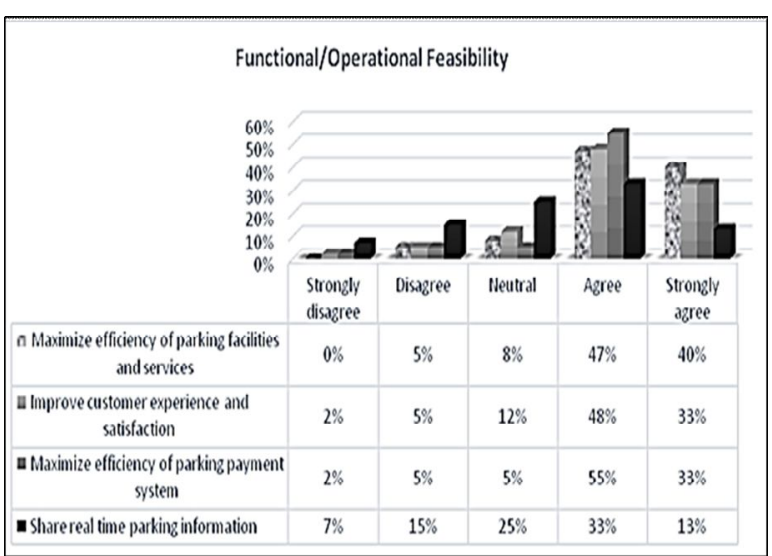

Figure 4.11: Functional/Operational feasibility

\section{SUMMARY, CONCLUSIONS AND RECOMMENDATIONS}

\subsection{Summary of the Findings}

\subsubsection{Demographic information}


The respondents consisted of Lulu East Africa and their clients. The staff was composed of two directors, a manager, four supervisors, other employees and the rest were other employees. Access to mobile devices is important a crucial factor in the implementation of the mobile parking management system not only for Lulu East Africa but also the employees. This is however not an issue in this study since majority of the respondents not only owned smart phones, tablets and or PDAs, but also access to conventional modes of mobile payment (such as Mpesa, Orange money and Airtel money) and other alternative forms of mobile payment.

\subsubsection{Current State of Management of Parking at Lulu East Africa}

Before improving the service delivery and the way parking management is done, it is important to analyse the current state of affairs. In regard the study determined that daily activities were conducted using a combination of comprised (automated) and manual methods. Notably, some clients had no idea which methods were used. Generally the satisfaction level of the state of affairs at Lulu were below average from both the clients and employees perspective with parking allocation and booking rating highest followed by payment processing. Communication with clients was rated poorly. It is worth noting here that majority of the respondents were neutral about the most of the categories of service delivery implying that changes needed to be done to ensure client satisfaction, gain a competitive edge and improve service delivery.

\subsubsection{Analysis of Adoption of Mobile Parking Management System}

Mobile parking management systems desirable features ensure efficiency and effectiveness and include; provision of real time parking information and mobile payment services respectively were the most sought after functionalities by majority of the respondents. In terms of perceived usefulness, the mobile parking management system would make it easier and faster to work, improve job performance and productivity, support critical aspects and give greater control over work. The system is perceived to be both easy to learn and operate, and easy for them to get it to do what they want to do. This perception could be attributed to the accessibility to mobile devices by the majority and the wide use of mobile payment.

There was a general intention, willingness and ability to use mobile parking management system in future in fact more than half of the respondents aim to replace the traditional system with the new management system. In terms of facilitating conditions that is, the individuals belief that an organizational and technical infrastructure exists to support technology use; the living and working environment supports the use of mobile parking management system and also using mobile parking management system is compatible with the life of majority of the respondents; there is also sufficient technological infrastructure to support mobile parking management system however the respondents were sceptical about the availability of help when they get problems in using mobile parking management system.

\subsubsection{Pre-feasibility Study}

This was the initial feasibility study conducted to as a guide to determine whether or not the pursuit for the subject technological adoption was worth further exploration. It also provides a basis for a detailed feasibility study. Lulu East Africa according to the survey has the technical capability to facilitate to fruition the adoption of mobile parking management system. It was established by the study that adopting the system would be a good business decision after a cost benefit analysis ad that that the company stood to gain competitive advantage leading to increased revenue as a result of the mobile management system adoption. The research established that adopting mobile parking management system will maximize efficiency of parking payment system and that of parking facilities and services and improve customer experience and satisfaction.

\subsection{Conclusions}

The management of parking at Lulu East Africa is currently a combination of manual and computerised, predominantly manual. Most of its publics are not satisfied with the service delivery and job performance. There is a mutual agreement that the management could use some improvements. There are numerous desired features of the mobile parking system that the respondents would like to be implemented including mobile payment, booking and reservation, and provision of real-time parking information. Generally Lulu East Africa is ready to adopt the mobile parking management system and its clients are willing and able to follow suit; with the right implementation approach and manipulation of the adoption variables as informed by this research there are high chances of success. A proper detailed personalised feasibly study however needs to be conducted by the respective parking service provider to ensure the fine details are considered to make informed decision.

\subsection{Recommendations}

Based on the research findings the researcher recommends that Lulu East Africa adopts the mobile parking management system with all the desired features. It is however imperative that they conduct an elaborate and detailed feasibility study so as to be able to make informed decisions. The new system and its features should be made public (consider marketing), the respondents concern for support in case they need help should also be factored and catered for. There would be need for training and support for both clients and staff especially in the initial stages of adoption.

Considering the fact that the respondents exhibited intention to use the new technology and the availability of facilitating environment, proactive efforts should be made 
to influence this factors such as proper marketing, education training and awareness. There is need to work on the weakness brought forth by this study in service delivery such as communicating with clients, and navigation and guidance. There will also be need for Lulu to work with stakeholders and partners to such as mobile network service providers and regulatory bodies ensure success and compliance.

\subsection{Suggestions for Further Research}

Further research is needed not only in the parking industry but also mobile technology especially with the wide use of mobile devices in the country. More studies need to be conducted on the adoption of an integrated mobile parking information system that works for both the private and public sector.

\section{REFERENCES}

1. Abu-dalbouh H., (2013). A questionnaire approach based on the technology acceptance model for mobile Tracking on patient progress applications. Journal of Computer Science 9 (6): 763-770, 2013 ISSN: 1549-3636. Science Publications

2. Andrews, Robert J. (2011) IBISWorld Industry Report 81293: Parking Lots \& Garages in the US. Santa Monica: IBISWorld.

3. Ajzen, I. (1991). The Theory of Planned Behaviour, Organizational Behaviour and Human Decision Processes 50, pp. 179-211.

4. Ajzen I. (2010). The Theory of Planned Behaviour, http://www.people.umass.edu/aizen/tpb.html Accessed August 2014.

5. Ajzen I. and M. Fishbein (1980) Understanding Attitudes and Predicting Social Behaviour Englewood Cliffs, NJ: Prentice-Hall, Inc.

6. Babbie E., (2012). The Practice of Social Research (13th edition). Belmont, Calif; Wadsworth Cengage Learning.

7. Bayless S. H. and Neelakantan R. (2012). Smart Parking and the Connected Consumer Opportunities for Facility Operators and Municipalities. The Intelligent Transportation Society of America (ITS America) research.

8. Blanchard S. and Fabrycky W. (2010). Systems Engineering \& Analysis. 5th ed Prentice Hall International Series in Industrial \& Systems Engineering.
9. British Parking Association, (BPA). (2012). Technology in the Parking industry. Parking practice notes Revised March 2012. British Parking Association.. West Sussex

10. Cooper R., Schindler P. (2011). Business Research Methods. McGraw-Hill/Irwin

11. Chwelos, P.et al. (2001). Research Report:

Empirical Test of an EDI Adoption Model. Information Systems Research (12)3, pp. 304321.

12. Davis F. (1989). Perceived Usefulness, Perceived Ease of Use, and User Acceptance of Information Technology. MIS Quarterly (13)3, pp. 319-342.

13. Davis F. et al (1989). User Acceptance of Computer Technology: A Comparison of Two Theoretical Models, Management Science (35)8, pp.982-1003.

14. Deci, E. and Ryan M. (2000). The "What" and "Why" of Goal Pursuits: Human Needs and the Self-Determination of Behavior, Psychological Inquiry (11)4, pp. 227-268.

15. Ervasti, M. and Helaakoski, H. (2010). Case study of application-based mobile service acceptance and development in Finland. Int. J. Information Technology and Management, 9 (3), 243-259

16. Flood et al, (2013). Trends in Mobile Payments in Developing and Advanced Economies. Reserve bank of Australia. Australia.

17. Griffin, R. and Pustay, M. (2010). International Business. New Jersey: Pearson Education Ltd.

18. Hart N. and, Gregor S. (2010). Information Systems Foundations: Theory Building in Information Systems. The Australian National University (ANU). ANU E Press

19. International Parking Institute- IPI. (2011) Emerging Trends in Parking: Report on a survey conducted by the International Parking Institute. 2011. (Accessed August, 2014).

20. Turner M., et al. (2010). Does the Technology Acceptance Model Predict Actual Use? A Systematic Literature Review. Information and Software Technology 52, pp. 463-479.

21. Kinyanjui E., (2010). Mobile Phone-Based Parking System. School of Computing and Informatics. University of Nairobi.

22. Korpelainen E., (2011). Theories of ICT System Implementation and Adoption - A Critical 
Review Working paper. Aalto University, Helsinki.

23. O'Brien A., and Marakas M. (2011). Developing Business/IT Solutions In Management Information Systems (pp. 488-489). New York, NY: McGraw-Hill/Irwin.

24. Pénicaud C (2013). State of the Industry: Results from the 2012 Global Mobile Money Adoption Survey', GSMA. Available at $<$ http://www.gsma.com/ mobilefordevelopment/wpcontent/uploads/2013/02/MMU_State_of_industr y.pdf $>$.

25. Robson C., (2011). Real World Research (3rd edition). John Wiley \& Sons. London.

26. Silverman, D. (2011). Interpreting qualitative data. London: SAGE Publications Ltd.

27. Walker A., (2011). Practical benefits of a hosted parking management solution. Presentation at the International Parking Institute's Conference \& Expo.

28. Wang A. and Wenbo, H., (2013). Parking Management Best Practices. Chicago: American Planning Association.

29. Yousafzai S. et al. (2007). Technology Acceptance: A Meta-Analysis of the TAM: Part 1. Journal of Modelling in Management (2) 3, pp. 251-280.

30. Yu C., (2012). Factors affecting individuals to adopt mobile banking: empirical evidence from the UTAUT model. Journal of Electronic Commerce Research, VOL 13, NO 2, 2012.

31. Zhu K., et al. (2004). Information Technology Payoff in EBusiness Environments: An International Perspective on Value Creation of EBusiness in the Financial Services Industry., Journal of Management Information Systems (21)1, pp.17-54. 